\title{
ANALISIS SOFT SKILL DAN HARD SKILL SERTA PENGARUHNYA TERHADAP OPTIMISME CALON LULUSAN PRODI MANAJEMEN UNIHAZ BENGKULU
}

\author{
Fauzan \\ Universitas Prof. DR. Hazairin, SH Bengkulu \\ fauzanunihaz@gmail.com
}

ABSTRAK

This research is explanatory research, intended to determine the relationship between soft skill and hard skill variables on the optimism of prospective graduates of Bengkulu Unihaz Management Study Program. The quantitative data of this study were obtained from questionnaires which were then processed into statistical analysis. The results of the analysis are known soft skill variables (X1) and hard skills (X2) have a strong and unidirectional relationship, and have a positive effect on the optimism variable of prospective graduates of the Unihaz Bengkulu study program. This is evidenced by the value of multiple correlation, multiple linear regression, t-test and f-test. Of the two independent variables hard skill contribution is greater than the soft skill. As a suggestion to improve students' hard skills and soft skills, they encourage them to be more active in research and community service, carry out excursion studies, namely visiting companies, entrepreneurs, crafts and other institutions that can foster their hard skills and soft skills, then directed to be more active in student organizations, youth and spirituality.

Keywords: Soft Skill, Hard Skill, Optimism of Prospective Graduates

\section{PENDAHULUAN}

Persaingan untuk mendapatkan pekerjaan bagi lulusan perguruan tinggi saat ini sangat kompetitif, karena semua instansi akan menerima karyawan yang berkompeten dan mumpuni. Demikian pula dengan lulusan program studi manajemen Universitas Prof. Dr. Hazairin, SH. (Unihaz) Bengkulu. Karyawan yang berkompeten dan mumpuni akan menunjukkan kinerja yang tinggi selalu berusaha menyelesaikan pekerjaannya dengan hasil optimal.

Kondisi ini sedikit menimbulkan rasa keragu-raguan calon lulusan prodi manajemen untuk memasuki dunia kerja. Adakalanya muncul perasaan pesimistis berupa pertanyaan profesi apa yang akan saya tekuni. Setelah lulus kuliah ingin melamar untuk bekerja atau akan berusaha menjadi intrerpreneur. Sebaliknya banyak pula diantara mereka yang mempunyai sikap optimis akan masa depan mereka, siap menyongsong masa depan, bekerja atau menjadi interpreneur.Optimisme merupakan keyakinan bahwa adanya kehidupan yang lebih baik dan keyakinan tersebut menjadi stimulus untuk bertindak agar mendapatkan hasil yang optimal. Optimis menjadi suatu paham yang dibakukan kedalam paradigma pemikiran."Shapiro (dalam Ghufron \& Risnawati : 2011) mendefinisikan optimisme masa depan lebih dari sekedar berpikir positif, bahwa optimisme diartikan sebagai kecendrungan untuk memandang segala sesuatu dan sisi kondisi baiknya, mengharapkan hasil yang paling memuaskan. Individu yang optimis percaya bahwa peristiwa positif yang membahagiakan bersifat permanen (akan terus terjadi sepanjang waktu) dan pervasif (akan terus terjadi dalam situasi berbeda-beda)". Hasil penelitian Sri Suwarsi dan Agustin Handayani (2017) "menunjukkan adanya hubungan positif yang sangat signifikan antara optimisme dengan problem focused coping pada mahasiswa yang sedang menyusun skripsi di Unisula artinya 
semakin tinggi optimisme maka semakin tinggi atau semakin baik pula problem focused coping pada mahasiswa yangsedang menyusun skripsi di Unisula".

Mahasiswa Prodi Manajemen Unihaz selama menempuh pendidikan dibangku kuliah dibekali dengan soft skill dan hard skill dengan maksud agar mereka sukses menjalankan perannya di tengah-tengah masyarakat dengan berbagai profesi. Soft skill merupakan kemampuan karakteristik yang dimiliki individu dalam merespon lingkungannya. The Collins English Dictionary (dalam Robles, 2012) "mendefinisikan soft skill sebagai kualitas yang dibutuhkan pekerja yang tidak terkait dengan pengetahuan teknis misalnya kemampuan untuk berinteraksi dengan orang lain dan kemampuan beradaptasi. Soft skill merupakan kemampuan intrapersonal seperti kemampuan untuk memanajemen diri dan kemampuan interpersonal seperti bagaimana individu berinteraksi dengan orang lain". Hasil penelitian fauzan (2019) terbukti bahwa soft skill sangat berpengaruh terhadap masa depan lulusan prodi manajemen Unihaz Bengkulu.

Hard skill merupakan penguasaan keterampilan teknis dari hasil pembelajaran yang berhubungan dengan suatu bidang ilmu tertentu. Hard skill seseorang dapat dilihat dari riwayat pendidikannya. Hard skill sangat erat kaitannya dengan keterampilan teknis yang melekat atau dibutuhkan untuk profesi tertentu. Hard skill mahasiswa prodi manajemen unihaz Bengkulu meliputi semua ilmu yang didapat sesuai dengan kurikulum yang diberlakukan. Hasil penelitian Ida Firdaus (2017) "Kemampuan non akademis itu biasa disebut soft skills dan kemampuan teknikal/akademis biasa disebut hard skills. Hard skills dan soft skills merupakan paduan yang harus terintegrasi dengan baik. Hard skills bisa di dapat di dunia pendidikan formal. Sedangkan soft skills di dapat bisa melalui pendidikan formal dan di luar pendidikan formal. Kemampuan soft skills memang sangatlah banyak. Variabel-variabel nya masih belum bisa teridentifikasikan dengan baik. Tapi bagi mahasiswa yang akan bekerja maupun membuat lapangan pekerjaan harus memiliki dan perlu mengembangkan kemampuan soft skills"

Dilatar belakangi oleh kondisi tersebut penulis meneliti dan merumuskan permasalahan seberapa besar soft skills dan hard skillsdapat mempengaruhi optimisme calon lulusan prodi manajemen dalam menghadapi masa depannya.

\section{LANDASAN TEORI}

Optimisme merupakan pola pikir positif yang digunakan orang dalam mengatasi masalah. Orang yang memiliki pola pikir positif selalu melihat sisi positifnya, realistis dan berusa menemukan solusi terbaik bila menghadapi maslah dan sangat yakin bahwa setiap masalah selalu ada jalan keluarnya. Scheier, Carver, dan Segerstrom (2010:879) "menyebutkan optimisme mencerminkan sejauh mana orang memegang harapan yang menguntungkan bagi mereka. Kesempatan untuk mencapai harapan adalah didasari pada keyakinan terhadap kemampuan atau potensi yang dimiliki individu dalam mencapai hal tersebut. Individu yang optimis adalah individu yang menyadari bahwa ia memiliki kemampuan untuk menjadi apa yang diharapkan. Hal-hal baik terkait tujuan, harapan yang positif dalam segala aspek kehidupan'.Sejalan dengan pernyataan tersebut Scheier \& Carver (2014:293) menyatakan bahwa optimisme sering diartikan sebagai keyakinan bahwa kejadian di masa yang akan datang memiliki nilai positif.

"Optimisme merupakan keyakinan yang dimiliki seseorang bahwa sesuatu yang baik akan terjadi dimasa depannya" (Smith, 2015). Arif (2016:157) "menyatakan aspek-aspek optimisme berhubungan erat dengan gaya penjelasan suatu peristiwa (explanatosy style), dimana hal ini berarti merupakan cara pandang individu terhadap peristiwa yang sedang ia hadapi yang dapat mambawanya menjadi individu yang memiliki optimisme atau justru pesimisme akan masa depan". 
Rasa optimisme calon lulusan prodi manajemen diharapkan akan timbul seiring dengan soft skill dan hard skill yang mereka miliki. 'Soft skill didefinisikan sebagai keterampilan, kemampuan, dan sifat-sifat yang berhubungan dengan kepribadian, sikap perilaku dari pada pengetahuan formal atau teknis" (Mahasneh \& Thabet, 2015). Sailah (Fauzan:2019) soft skills didefinisikan sebagai "Personal and interpersonal behaviour that develop and maximize human performance (e.g. coaching, team building, initiative, decision making, etc.). Soft skills does not include technical skill such as financial computing and assembly skills. Definisi tersebut dapat dimaknai bahwa perilaku hubungan antar pribadi dan dengan pribadinya sendiri dikembangkan dan kinerja manusianya dioptimalkan (misalnya, forum pelatihan, bekerjasama dalam tim, inisiatif, pengambilan keputusan, komunikasi, kemampuan beradaptasi, conflict solution, kepemimpinan, pemecahan masalah, dan lain-lain.)"

Soft skills adalah keterampilan seseorang dalam berhubungan dengan orang lain (interpersonal skills) dan keterampilan dalam mengatur dirinya sendiri (intrapersonal skills) untuk kerja secara maksimal. Berthal mengemukakan Muqowim. (2012 : 5) "Soft skills diartikan sebagai perilaku personal dan interpersonal yang mengembangkan dan memaksimalkan kinerja manusia". 'Soft skill adalah karakteristik yang mempengaruhi hubungan pribadi dan profesional seorang individu dan bekerja yang berkaitan dengan prospek karir" (Vyas \& Chauhan, 2013). Elfindri dkk menjelaskan bahwa "soft skills merupakan sebuah keterampilan dan kecakapan hidup yang harus dimiliki baik untuk sendiri, berkelompok, atau bermasyarakat, serta berhubungan dengan Sang Pencipta. Soft skills sangat diperlukan untuk kecakapan hidup seseorang”. (2010:10).

Hard skill adalah bagian dari rangkaian keterampilan yang diperlukan untuk suatu pekerjaan. Hard skill merupakan suatu keahlian yang diperlukan bagi seorang individu untuk berhasil melakukan pekerjaan. Hard skill bisa diperoleh melalui program pendidikan dan pelatihan formal, termasuk kuliah, magang, kelas pelatihan jangka pendek, kursus online, dan program sertifikasi, serta pelatihan di tempat kerja. Diknas: 2008 "Hard skill, yaitu penguasaan ilmu pengetahuan, teknologi dan keterampilan teknis yang berhubungan dengan bidang ilmunya. Hard skill merupakan penguasaan keterampilan teknis dari hasil pembelajaran yang berhubungan dengan suatu bidang ilmu tertentu". (Zulkifli Rasid, Berhard Teswel, dkk : 2018)

Pengertian hard skill adalah kemampuan yang dapat dipelajari yang diperoleh dan ditingkatkan melalui latihan, pengulangan, dan pendidikan. Hard skill mahasiswa didapat dari aktivitas belajar mengajar dibanku kuliah. Shivanjali (2012) "Hardskills are specific, teachable abilities that may be required in a given context, such as a job training, which will help an individual to execute their profession. Hardskill is a basic and fundamental as it helps an individual to develop knowledge in a particular domain". Pengusaha dan perekrut paling sering mencari hard skill ini dalam resume profesional calon karyawan. Setiap hard skill yang dimiliki seseorang didukung dengan sertifikat, gelar, atau kualifikasi lain yang menunjukkan tingkat pencapaian. Hasil penelitian Z.Rasid.,B.Tewal, dkk menunjukkan bahwa adanya pengaruh positif variabel Hard Skill dan Soft Skill terhadap Kinerja Karyawan Perum Damri Manado, demikian juga dengan penelitian yang dilakukan oleh M.Untung Manara dengan judul Hard Skills dan Soft Skills pada Bagian Sumber Daya Manusia di Organisasi Industri.

Kerangka pikir dalam penelitian ini dapat digambarkan dalam skema penelitian berikut: 


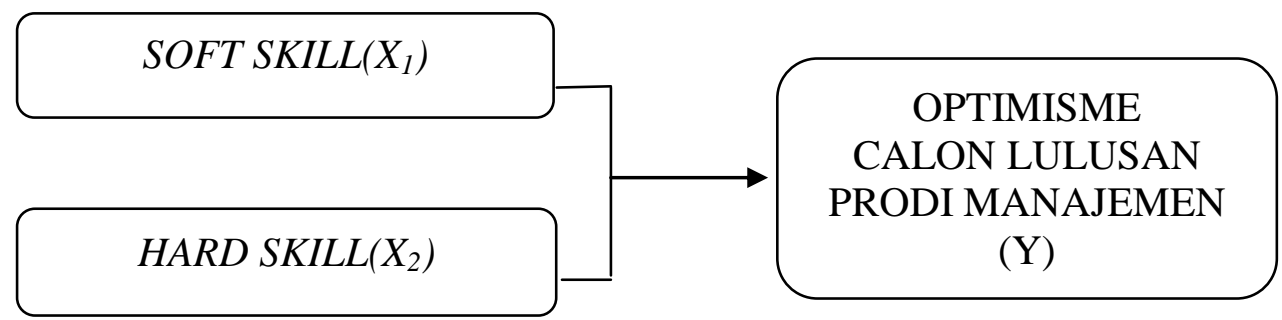

Hipotesis penelitian ini :

$\mathrm{H}_{1}$ : Adanya pengaruh soft skill terhadap Optimisme Calon Lulusan prodi manajemen unihaz Bengkulu.

$\mathrm{H}_{2}$ : Adanya pengaruh Hard Skill terhadap Optimisme Calon Lulusan prodi manajemen unihaz Bengkulu.

$\mathrm{H}_{3}$ : Adanya pengaruh soft skill dan Hard Skill terhadap Optimisme Calon Lulusan prodi manajemen unihaz Bengkulu.

\section{Metodologi Penelitian}

Penelitian ini bersifat eksplanatory risearach, yaitu melihat hubungan variabel pengetahuan Soft Skill $\left(\mathrm{X}_{1}\right)$ dan Hard Skill $\left(\mathrm{X}_{2}\right)$ terhadap Optimisme Calon Lulusan Prodi Manajemen (Y) kemudian menguji hipotesa. Dalam penelitian ini data yang digunakan adalah data kuantitatif, dimana data tersebut diperoleh dari hasil penyebaran kuesioner (data primer) kepada responden untuk diolah kedalam analisa statistik.

Populasi dalam penelitian ini adalah calon lulusan prodi manajemen Unihaz Bengkulu (mahasiswa yang sedang melaksanakan penyusunan skripsi pada semester genap Tahun akademik 2019-2020. Teknik pengambilan sampel non probability sampling, dengan metode sensus, dimana sampel diambil dari keseluruhan populasi yaitu 83 orang calon lulusan prodi manajemen.

Alat analisa yang digunakan dalam penelitian ini adalah (1) Analisa regresi linear berganda, yang digunakan untuk mengetahui seberapa besar pengaruh antara variabel soft skill $\left(\mathrm{X}_{1}\right)$ dan Hard Skill $\left(\mathrm{X}_{2}\right)$ dengan variabel Optimisme Calon Lulusan (Y). Menurut Sugiyono (2013:269) "persamaan regresi linear berganda dengan dua variabel independen adalah sebagai berikut : $\mathrm{Y}=\mathrm{b}_{0}+\mathrm{b}_{1} \mathrm{X}_{1}+\mathrm{b}_{2} \mathrm{X}_{2}+\mathrm{e}$ (2) "korelasi berganda untuk melihat tingkat keeratan atara variabel-varibel independen dengan variabel dependent. (3) koefisein determinasi akan memberikan informasi seberapa besar persentase variasi variabel bebas yang digunakan dalam model mampu menjelaskan variasi variabel terikat". (Prayitno : 2013 : 143). (4) "Pengujian hipotesis yang digunakan dalam penelitian ini ialah uji signifikansi simultan atau uji statistik $F$ dan uji signifikansi parameter individual atau uji statistik t. Uji $F$ untuk menunjukkan apakah semua variabel independen secara simultan berpengaruh pada variabel dependen" Uji t dipakai untuk mengetahui seberapa besar pengaruh dari variabel independen secara parsial terhadap variabel dependen.

\section{Hasil dan Pembahasan}

Hasil analisa spss diperoleh nilai regresi berganda, korelasi berganda, diterminasi, uji$\mathrm{t}$, dan uji-f, dengan interpelasi sebagai berikut: 
Coefficients $^{\mathrm{a}}$

\begin{tabular}{|l|r|r|r|r|r|}
\hline & \multicolumn{2}{|c|}{$\begin{array}{c}\text { Unstandardized } \\
\text { Coefficients }\end{array}$} & $\begin{array}{c}\text { Standardized } \\
\text { Coefficients }\end{array}$ & \multirow{2}{*}{ T } & \multicolumn{1}{c|}{ Sig. } \\
\cline { 2 - 5 } Model & \multicolumn{1}{|c|}{ B } & Std. Error & \multicolumn{1}{c|}{ Beta } & \multicolumn{1}{c|}{ T } \\
\hline 1 (Constant) & 14.095 & 1.333 & & 10.574 & .000 \\
Soft Skill & .164 & .065 & .266 & 2.519 & .014 \\
Hard Skill & .208 & .063 & .347 & 3.294 & .001 \\
\hline
\end{tabular}

a. Dependent Variable: Optimisme Calon Lulusan

Tabel Coefficients ${ }^{\mathrm{a}}$ menghasilkan persamaan regresi $\mathrm{Y}=14,095+0,164 \mathrm{X}_{1}+0,208$ $\mathrm{X}_{2}$. Artinya bila soft skill dan Hard Skill diangap tidak ada maka nilai optimisme calon lulusan prodi manajemen sebasar 14,095. Koefisien variabel soft skill sebesar 0,164 artinya apabila variabel soft skill ditingkatkan sebesar satu satuan maka optimisme calon lulusan prodi manajemen akan meningkat sebesar 0,164 satuan. Koefisien variabel hard skill sebesar 0,208 artinya apabila hard skill ditingkatkan sebesar satu satuan maka optimisme calon lulusan prodi manajemen akan meningkat sebesar 0,208 satuan.

Dilihat dari kontribusi kedua variabel di atas, terlihat bahwa hard skill memberikan kontribusi yang lebih besar yaitu 0,208 sedangkan variabel soft skill sebesar 0,164. Hal ini dapat dimaklumi bahwa calon lulusan prodi manajemen masih terfocus pada ilmu yang didapat dari perkuliahan dan dijadikan sandaran untuk mendapatkan pekerjaan. Kemudian bila mereka akan mengikuti seleksi penerimaan pegawai baik instansi pemerintah maupun swasta soal-soal test berdasarkan hard skill sebagaimana yang mereka dapatkan dibangku perkuliahan. Sementara soft skill hanya mereka peroleh didalam organisasi kemahasiswaan dan organisasi-organisasi kepemudaan lainnya.

Hard skill adalah kemampuan teknis yang dikuasai, jadi kemampuan teknik yang dikuasai oleh lulusan prodi manajemen Unihaz sesuai dengan learning outcome (LO)adalah:

1. Aspek Pengetahuan Spesifik, terdiri dari:

a. Mampu mengaplikasikan bidang keahlian manajemen dan memanfaatkan IPTEKS pada bidangnya dalam penyelesaian masalah serta mampu beradaptasi terhadap situasi yang dihadapi

b. Menguasai konsep teoritis bidang pengetahuan Manajemen secara umum dan konsep teoritis bagian khusus dalam bidang pengetahuan tersebut secara mendalam, serta mampu memformulasikan penyelesaian masalah prosedural

c. Mampu mengambil keputusan yang tepat berdasarkan analisis informasi dan data, dan mampu memberikan petunjuk dalam memilih berbagai alternatif solusi secara mandiri dan kelompok

2. Aspek Keterampilan spesifik, terdiri dari:

a. Mampu mengaplikasikan ilmu manajemen

b. Mampu memanfaatkan ilmu pengetahuan dan teknologi pada bidang manajemen

c. Mampu beradaptasi terhadap situasi yang dihadapi

d. Menguasai konsep teoritis bidang ilmu Manajemen secara umum

e. Menguasai konsep teoritis manajemen SDM, Keuangan, Operasi dan Pemasaran secara mendalam

f. Memformulasikan penyelesaian masalah prosedural secara manajerial

g. Mampu mengambil keputusan yang tepat berdasarkan analisis informasi dan data

h. Mampu memberikan petunjuk dalam memilih berbagai alternative solusi secara mandiri 

adalah :

Sedangkan soft skill sesuai dengan learning outcome program studi manajemen a. Bertanggung jawab secara profesional dan etik terhadap pencapaian hasil kerja individu. b. Bertanggung jawab secara profesional dan etik terhadap pencapaian hasil kelompok.

Uraian tentang hard skill dan soft skill tersebut di atas, secara tidak langsung membenarkan dan mendukung bahwa kontribusi hard skill lebih besar dari soft skill terhadap optimisme calon lulusan prodi manajemen Unihaz Bengkulu. Hard skill merupakan kemampuan untuk menguasai ilmu pengatahuan teknologi dan keterampilan teknis dalam mengembangkan intelligence quotient yang berhubungan dengan bidangnya. Proses pembelajaran di perguruan tinggi lebih menitik beratkan pada aspek kognitif. Hal ini dapat dilihat pada prestasi mahasiswa yang ditunjukkan oleh indeks prestasi (IP). Indeks prestasi dibuat berdasarkan hasil penilaian dari evaluasi dosen terhadap mahasiswa dalam proses pembelajaran.

Kemampuan mahasiswa yang ditunjukkan berdasarkan indeks prestasi seperti inilah yang sering disebut sebagai kemampuan hard skill.Soft skill yaitu kemampuan seseorang dalam berhubungan dengan orang lain (interpersonal skills) dan kemampuan seseorang dalam mengatur dirinya sendiri (intrapersonal skills) serta kemampuan tambahan seseorang dalam kepercayaan/kepedulian baik terhadap penciptanya maupun orang lain (ekstrapersonal skills).

\begin{tabular}{|l|r|r|r|r|}
\hline \multicolumn{5}{|c|}{ Model Summary $^{\mathbf{b}}$} \\
\hline Model & R & R Square & $\begin{array}{c}\text { Adjusted R } \\
\text { Square }\end{array}$ & $\begin{array}{c}\text { Std. Error of } \\
\text { the Estimate }\end{array}$ \\
\hline 1 & $.519^{\mathrm{a}}$ & .269 & .251 & .93939 \\
\hline
\end{tabular}

a. Predictors: (Constant), Hard Skill, Soft Skill

b. Dependent Variable: Optimisme Calon Lulusan

Regresi linear berganda diperoleh koefisien korelasi berganda $R=0,519$. Nilai tersebut menunjukkan bahwa hubungan antara variabel soft skill $\left(\mathrm{X}_{1}\right)$ dan hard skill $\left(\mathrm{X}_{2}\right)$ dengan variabel optimise calon lulusan prodi manajemn (Y) sangat erat dan searah. Artinya semakin tinggi soft skill dan hard skill dimiliki oleh calon lulusan prodi manajemen maka akan semakin tinggi pula tingkat optimisme mereka setelah lulus nantinya dan sebaliknya.

Optimisme mengandung pengertian calon lulusan itu akan siap meniti kaier, baik bekerja dengan pihak lain ataupun menjadi interpreniur. Koefisien diterminasi diperoleh nilai 0,269 , artinya $26,9 \%$ soft skill dan hard skill dapat mempengaruhi optimisme calon lulusan prodi manajemen sedangankan $73,1 \%$ dipenaruhi oleh varibel lain diluar variabel yang diteliti dan dapat menjadi topik penelitian berikutnya atau bagi peneliti yang lain.

\begin{tabular}{|c|c|c|c|c|c|c|}
\hline \multicolumn{2}{|c|}{ Model } & $\begin{array}{l}\text { Sum of } \\
\text { Squares }\end{array}$ & df & $\begin{array}{l}\text { Mean } \\
\text { Square }\end{array}$ & $\mathrm{F}$ & Sig. \\
\hline \multirow[t]{3}{*}{1} & Regression & 26.030 & 2 & 13.015 & 14.748 & $.000^{\mathrm{a}}$ \\
\hline & Residual & 70.597 & 80 & .882 & & \\
\hline & Total & 96.627 & 82 & & & \\
\hline
\end{tabular}

a. Predictors: (Constant), Hard Skill, Soft Skill

b. Dependent Variable: Optimisme Calon Lulusan 
Pengujian hipotesa secara parsial (uji-t) menunjukkan bhwa secara parsial baik soft skill maupun hard skill berpengaruh positif terhadap optimisme calon lulusan prodi manajemen Unihaz Benkulu. Hal ini dapat dilihat dari angka t-hitung untuk variabel soft skill 2,519 dengan significant $0,014<0,05$, sedangkan varibel hard skill nilai t-hitung sebesar 3,294 dengan significant 0,001. Angka t-hitung hard skill lebih besar dari soft skill dan signifikansi hard skill lebih kecil dari soft skill, hal ini sejalan atau memperkuat pernyataan bahwa hard skill kontribusinya terhadap optimisme calon lulusan prodi manajemen lebih besar dari soft skill.

Pengujian hipotesa secara simultan (uji-f) diperoleh nilai f-hitung 14,748 dengan signifikansi 0,000, terbukti bahwa soft skill dan hard skill berpengaruh positif terhadap optimisme calon luluran prodi manajemen Unihaz Bengkulu.

\section{Simpulan}

Hasil analisa menunjukkan bahwa soft skill dan hard skill berpengaruh signifikan terhadap optimisme calon lulusan prodi manajemen untuk meniti karir setelah menyelesaikan pendidikannya. Kontribusi terhadap optimisme calon lulusan prodi manajemen hard skilllebih besar dari soft skill. Demikian juga terhadap uji parsial hard skill lebih signifikan dari pada soft skill.

Sedangkan uji secara simultan menunjukkan bahwa kedua variabel indevenden tersebut berpengaruh secara significat terhadap variabel optimisme calon lulusan prodi manajemen Unihaz Bengkulu. Demikian juga uji simultan menunjukkan kedua variabel indevenden tersebut juga berpengaruh signifikan terhadap optimisme calon lulusan prodi manajemen Unihaz Bengkulu.

Sebagai saran untuk meningkatkan hard skill dan soft skill mahasiswa mendorong mereka untuk lebih aktif dalam penelitian dan pengadian kepada masyarakat, melaksanakan studi ekskursi yaitu berkunjung keperusahaan, wiraswasta, kerajinan dan instansi lain yang dapat memupuk hard skill dan soft skill mereka, kemudian diarahkan untuk lebih aktif dalam organisasi kemahasiswaan, kepemudaan dan kerohanian.

\section{DAFTAR PUSTAKA}

Arif, I.S. (2016). Psikologi Positif: Pendekatan Saintifik Menuju Kebahagiaan. Jakarta, Gramedia Pustaka Utama.

Carver, C.S., Scheier, M.F., \& Segerstrom, S.C. (2010). Optimism. Clinical Psychology Review, 30, 879-889.

Elfindri dkk. 2010. Soft Skill Untuk Tenaga Pendidik. Jakarta: Baduose Media.

Fauzan. 2019. Pengaruh Soft Skill dan Locus of Control Internal Terhadap Kesiapan fresh Graduate Dalam Era Industri 4.0 (Studi Pada Prodi Manajemen Unihaz Bengkulu. Jurnal CRMJ ISSN 2621-1092. Vol 2 Nomor 2. Fakultas Ekonomi Prodi Manajemen UNIHAZ Bengkulu

Ghufron, M. N.\& Risnawita, S. R. (2011). Teori - teori psikologi. Yogyakarta: Ar-ruz Media Group.

Mahasneh, J., \& Thabet, W. (2015). Rethinking Construction Curriculum: A Descriptive Cause Analysis for Soft Skills Gap. ASC Annual International Conference Proceedings, 1-8.

Muqowim (2012) Pengembangan Soft Skill Guru. Yogyakarta: Pedagogia.

Priyatno. (2013). Mandiri Belajar Analisis Data Dengan SPSS. Jakarta, Mediakom.

Robles. (2012). Executive perceptions of the top 10 soft skills needed in today's workplace. Business Communication Quarterly, 75, 453-465. 
Shivanjali. 2010. Softskills Training Versus Hard Skills Training. International Journal in Multidisciplinary and Academic Research (SSIJMAR),Vol. 1, No. 3, SeptemberOctober (ISSN 2278 - 5973)

Smith, L. M. (2015). The relathionship between optimism and markers of psychological health in cologiate atheletes. University Nort Carolina.

Sri Suwarsi dan Agustin Handayani. (2017). Hubungan Antara Optimisme Dan Problem Focused Coping pada Mahasiswa Yang Sedang Menyusun Skripsi Proyeksi, Vol.12

(1) Fakultas Psikologi Universitas Islam Sultan Agung Semarang ISSN : 1907-8455.

Sugiyono, (2013), metodelogi penelitian bisnis, Bandung, CV Alfabeta.

Untung Manara, 2014. Hard Skills dan Soft Skills pada Bagian Sumber Daya Manusia di Organisasi Industri, Jurnal Psikoloi Tabularasa, Volume 9, No.1, April: 37-47 Fakultas Psikologi, Universitas Merdeka Malang.

Vyas, P., \& Chauhan, G. S. (2013). The Preeminence Of Soft Skills: Need For Sustainable Employability. Journal of Social Science \& Interdisciplinary Research, 2(5), 124-131.

Waskito, AM. (2013). The power of optimism: membangun harapan dan semangat umat berdasar Al Qur'an,sunnah,dan kehidupan orang shaleh. Jakarta: Pustaka Al kautsar.

Z.Rasid.,B.Tewal.,C.Kojo. (2018). Penaruh Hard Skill dan Sof Skill Terhadap Kinerja Karyawan Perum Damri Manado. Fakultas Ekonomi dan Bisnis, Jurusan Manajemen Universitas Sam Ratulangi Manado Jurnal EMBA Vol.6 No.2. ISSN 2303-1174 